\title{
The Differentiation of Streptococcus faecalis and S. faecium
}

\author{
BY R. WHITTENBURY \\ Department of Bacteriology, School of Agriculture, Edinburgh
}

(Received 10 September 1964)

\begin{abstract}
SUMMARY
Enterococci mainly from laboratory collections were separated by established and new or modified tests into two distinct species, Streptococcus faecalis and $S$. faecium. Of the established tests only reducing activity and potassium tellurite tolerance completely differentiated the organisms. Of the additional tests the most useful were fermentation of glycerol in a soft agar medium containing fumarate, $\mathrm{H}_{2} \mathrm{O}_{2}$ formation from polyhydroxy alcohols and the ability to ferment them, $\mathrm{H}_{2} \mathrm{O}_{2}$ formation on a basal medium containing no added specific energy source, citrate fermentation and dissimilation of malate in the presence of glucose. Catalase activity and the ability to use malate as an energy source were also useful tests but did not completely differentiate the organisms.
\end{abstract}

\section{INTRODUCTION}

The enterococci (from which are excluded the Streptococcus bovis-equinus complex) appear to be divisible into two major physiological and biochemical groups, one represented by $S$. faecalis and the other by $S$. faecium. Evidence for such a division can be found in the work of Orla-Jensen (1919, 1943); Olsen (1949); Skadhauge (1950); Sharpe \& Shattock (1952); Shattock (1955); Barnes (1956); Lake, Deibel \& Niven (1957); Deibel, Lake \& Niven (1963). The practical necessity of being able to distinguish the two species has become increasingly evident in relation to the detection of faecal pollution of water supplies and foods. Recent work on the distribution of these species by Kjellander (1960), for instance, revealed that $S$. faecalis was the more numerous species in human faeces and $S$. faecium in animal faeces. Tests for separating $S$. faecalis from $S$. faecium before those devised by Deibel et al. (1963) were few and not always satisfactory. The purpose of the present work was to develop new tests which, in conjunction with those described earlier, would assist in the identification of the enterococci. Since the completion and publication of this work in thesis form (Whittenbury, 1961), Deibel et al. have reported a comprehensive study of this group of organisms, reviewing the development of its taxonomy and describing new tests which differentiate $S$. faecalis from $S$. faecium. Some of the tests described in the present work are similar to those devised by Deibel $e t$ al., but as they were devised independently and differ in certain respects from those of Deibel $e t$ al. it is considered that they are still worth reporting. Among the organisms studied were strains thought to be typical of $S$. faecalis, $S$. faecium and $S$.durans, and strains which possessed unusual characteristics. 


\section{METHODS}

Organisms. The strains and their sources are listed in Table 1.

Media. Basal medium agar was: meat extract (Lab-Lemco), 0.5 g.; peptone (Evans), 0.5 g.; yeast extract (Difco), 0.5 g.; Tween 80, 0.05 ml.; $\mathrm{MnSO}_{4} \cdot 4 \mathrm{H}_{2} \mathrm{O}$, $0.01 \mathrm{~g}$.; agar (Davis), $1.5 \mathrm{~g}$. ; in $100 \mathrm{ml}$. tapwater, adjusted to $\mathrm{pH} 6.5$ and autoclaved at $121^{\circ}$ for $15 \mathrm{~min}$.

Table 1. Source and identification of cultures used

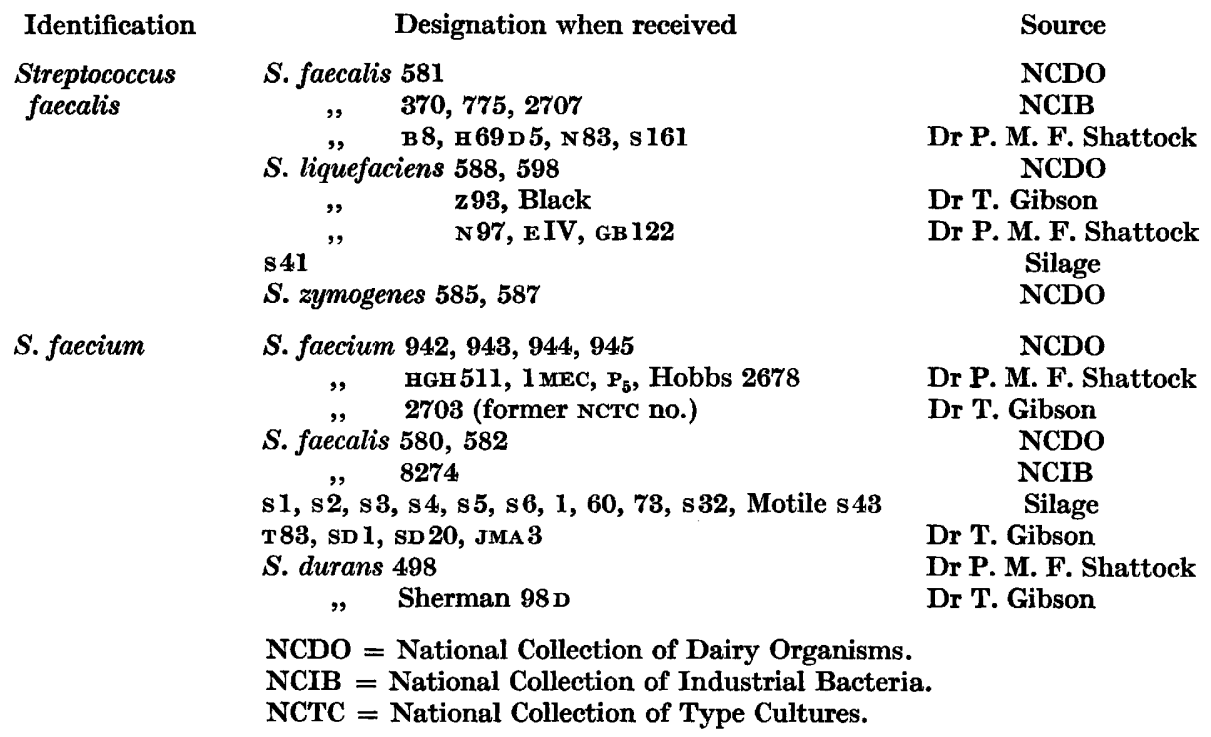

Liquid medium was similar to the basal medium agar but without agar.

'Inoculum' medium was similar to basal medium agar but with the agar omitted and glucose $0.5 \%(\mathrm{w} / \mathrm{v})$ added.

Soft agar medium, which was used for showing oxygen relationships and fermentative activities, was prepared and inoculated as described previously (Whittenbury, 1963) with the exception that the bromcresol purple content was doubled. Sugars and polyhydroxy alcohols were prepared as Seitz-filtered distilled water solutions and added to give a final concentration in the media of $0.5 \%(w / v)$.

Arginine hydrolysis. The method of Niven, Smiley \& Sherman (1942) was routinely used with the exception that Tween 80 was included in the medium. In some studies liquid medium containing L-arginine monohydrochloride $0.3 \%(\mathrm{w} / \mathrm{v})$, with or without glucose $0 \cdot 1$ or $1 \%(\mathrm{w} / \mathrm{v})$, adjusted to $\mathrm{pH} \mathrm{6.5}$, was used. Ammonia production was determined with Nessler's reagent on a spot plate and glucose disappearance with Benedict's reagent. Cultures were held at $37^{\circ}$ in a water bath Growth was measured nephelometrically at 10-15 min. intervals at the end of the lag phase; $\mathrm{pH}$ values were measured electrometrically.

Serine hydrolysis. Liquid medium containing $\mathrm{L}$-serine $0 \cdot 3 \%(\mathrm{w} / \mathrm{v})$ was adjusted to pH 6.5. Ammonia production was determined by Nessler's reagent and acetoin 
(indicating dissimilation of pyruvate, the deamination product) by Barritt's (1936) modification of the Voges-Proskauer test.

Ability to initiate growth at $\boldsymbol{p H} \mathbf{9 \cdot 6}$. The method of Chesbro \& Evans (1959) was used. Additional experiments with the same medium converted to a soft agar were also done.

Tolerance of potassium tellurite. Basal medium agar containing glucose $\mathbf{0 . 5} \%$ $(w / v)$, tellurite $0 \cdot 04 \%(w / v)$ (the concentration recommended by Skadhauge, 1950), adjusted to $\mathrm{pH} \mathrm{6.5,} \mathrm{was} \mathrm{used.} \mathrm{The} \mathrm{results,} \mathrm{erratic} \mathrm{at} \mathrm{first,} \mathrm{became} \mathrm{constant}$ when the concentration of the meat extract in the medium was doubled.

Reduction of 2,3,5triphenyltetrazolium chloride (tetrazolium). This test was adapted from that described by Barnes (1956). Liquid medium containing glucose $0.5 \%(\mathrm{w} / \mathrm{v})$ was adjusted to $\mathrm{pH} 6.0$. Tetrazolium, $0.01 \%(\mathrm{w} / \mathrm{v})$ final concentration, was added from a stock solution heated at $100^{\circ}$ for $15 \mathrm{~min}$. A heavy inoculum, 3 capillary pipette drops of turbid culture, was added to $4 \mathrm{ml}$. medium in a test tube. The cultures, incubated at $30^{\circ}$, were examined at $8 \mathrm{hr}$. Positive cultures were coloured a deep magenta, whilst cultures regarded as negative were either colourless or faintly pink.

Reduction and tolerance of methylene blue in milk and the reduction of litmus in milk. A heavy inoculum, 3 capillary pipette drops, was added to the milk media which were incubated at $30^{\circ}$ and read at $8 \mathrm{hr}$.

Haemolysis. Brown's (1919) method was followed, with nutrient agar containing $\mathrm{NaCl} 0.5 \%(\mathrm{w} / \mathrm{v})$ and defibrinated horse blood $3 \%(\mathrm{w} / \mathrm{v})$. Poured agar plates were incubated for 2 days at $30^{\circ}$ and refrigerated overnight. Further tests were made with ox blood in the basal medium agar containing $\mathrm{NaCl} 1.0 \%(\mathrm{w} / \mathrm{v})$.

Hydrogen peroxide formation, pseudocatalase and catalase tests. Methods and media (heated blood $o$-dianisidine agar, heated blood agar and glucose agar) described previously (Whittenbury, 1964) were used. In testing for $\mathrm{H}_{2} \mathrm{O}_{2}$ formation it was essential that the inoculum be taken from aerobically incubated slope cultures.

Malate and citrate dissimilation. Ability to dissimilate malate in the presence and absence of glucose was determined. Liquid medium was used containing DL-malic acid $4.0 \%(\mathrm{w} / \mathrm{v})$; bromcresol purple, $2 \cdot 8 \mathrm{ml}$. of a $1 \cdot 6 \%(\mathrm{w} / \mathrm{v})$ ethanolic solution/l. (unless acetoin was being tested for); glucose 1-2.0\% (w/v); adjusted to $\mathrm{pH} 6.0$ with $\mathrm{KOH}$ and distributed in $4 \mathrm{ml}$. amounts in $5 \times \frac{1}{2}$ in. test tubes containing Durham tubes. Water agar seals were added to the inoculated tubes; the function of the Durham tubes was to support the seals. Action on malate was judged by increase in $\mathrm{pH}$ value, gas $\left(\mathrm{CO}_{2}\right)$ production, and, in the absence of glucose, by increase in the amount of growth over that in the basal medium and by acetoin production.

Citrate dissimilation was examined in similar media to those used in the study of action on malate. Citrate (potassium citrate $3.0 \%, \mathrm{w} / \mathrm{v}$ ) was added and the medium adjusted to $\mathrm{pH} \mathrm{8.0} \mathrm{for} \mathrm{routine} \mathrm{use.} \mathrm{Action} \mathrm{on} \mathrm{citrate} \mathrm{in} \mathrm{the} \mathrm{absence} \mathrm{of}$ glucose was judged by gas production, acetoin formation, increase in $\mathrm{pH}$ measured electrometrically, and by increase of growth over that in the basal medium. In the presence of glucose (medium adjusted to $\mathrm{pH} \mathrm{6.0)}$ gas $\left(\mathrm{CO}_{2}\right)$ production indicated action on citrate.

To examine for gas production from citrate and malate, each tube was sharply tapped to initiate effervescence. In cultures above pH 6.5 bromcresol purple was 
frequently bleached except when the culture was in contact with the atmosphere (the top $2 \mathrm{~mm}$. of the agar seal) where it remained oxidized, so allowing an estimate of $\mathrm{pH}$ change to be made in these circumstances.

A relatively high concentration of potassium in the medium is essential for active dissimilation of citrate and malate (Keddie, 1959). Consequently pH adjustments of malate media were always made with $\mathbf{K O H}$ and potassium citrate was used in the citrate media.

Temperature of incubation. Unless otherwise stated, incubation was at $30^{\circ}$.

\section{RESULTS}

The identification of the organisms as enterococci was confirmed by established physiological and biochemical tests which collectively separate the enterococci from other streptococci. These tests are: ability to tolerate $6.5 \% \mathrm{NaCl}$, to hydrolyse

Table 2. Differentiation of the organisms by currently used tests

\begin{tabular}{|c|c|c|}
\hline & $\begin{array}{c}\text { Streptococcus } \\
\text { faecalis } \\
\text { (no. positive } \\
\text { out of } \\
18 \text { strains tested) }\end{array}$ & $\begin{array}{c}\text { Streptococcus } \\
\text { faecium } \\
\text { (no. positive } \\
\text { out of } \\
29 \text { strains tested) }\end{array}$ \\
\hline \multicolumn{3}{|l|}{ Fermentation of: } \\
\hline Arabinose & 4 & 20 \\
\hline Melibiose & $\mathbf{0}$ & 18 \\
\hline Melezitose & $12 *$ & $\mathbf{0}$ \\
\hline Sorbitol & 18 & $2 \dagger$ \\
\hline Glycerol (in the absence of fumarate) & $18 \ddagger$ & 24 (aerobic) \\
\hline \multicolumn{3}{|l|}{ Tolerance of: } \\
\hline Tellurite & 18 & $\mathbf{0}$ \\
\hline \multicolumn{3}{|l|}{ Reduction of: } \\
\hline Methylene blue (1.0\%) & 18 & $\mathbf{0}$ \\
\hline Tetrazolium (0.01 \%) & 18 & $\mathbf{0}$ \\
\hline Litmus & 18 & $\mathbf{0}$ \\
\hline
\end{tabular}

arginine, to withstand heating at $63^{\circ}$ for $30 \mathrm{~min}$., to initiate growth at $\mathrm{pH} 9 \cdot 6$ and to grow at $10^{\circ}$ and $45^{\circ}$. Only the ability to grow at $\mathrm{pH} 9.6$ and at $10^{\circ}$ and $45^{\circ}$ was common to all strains. Where growth at $\mathrm{pH} 9 \cdot 6$ was tested by the modification of the method of Chesbro \& Evans (1959) in which the medium was made into a soft agar, most strains formed a uniform dense growth but Streptococcus durans and similar strains gave rise only to a few colonies, suggesting that most of the organisms had not survived. The 'survivors' did not seem to be mutants adapted to alkaline conditions since inocula prepared from them gave only a few colonies, as before. Of the remaining tests arginine hydrolysis was the most useful since only one strain (the motile enterococcus) was negative. This strain was at one time able to hydrolyse arginine but has lost this property within a 4-year period. 
The organisms were next subjected to tests commonly used for the differentiation of the enterococci. The results (Table 2) distinguished two main groups which will be discussed as Streptococcus faecalis and $S$. faecium. Only the tellurite and reduction tests differentiated the groups completely and the reduction tests (see Methods) had to be modified (Whittenbury, 1956) to achieve a separation. The rate at which tetrazolium, methylene blue and litmus were reduced proved to be a more useful criterion than the ability to reduce these substances; this also seems to have been the view of other workers including Deibel et al. (1963). The additional tests that were used are described below and the results are given in Table 3.

Table 3. Differentiation of the organisms by additional tests

$\begin{array}{lcc} & \begin{array}{c}\text { Streptococcus } \\ \text { faecalis }\end{array} & \begin{array}{c}\text { Streptococcus } \\ \text { faecium }\end{array} \\ \begin{array}{l}\text { Fermentation of glycerol in the presence of } \\ \text { fumarate }\end{array} & + & A \\ \mathrm{H}_{2} \mathrm{O}_{2} \text { from: } & - & + \\ \quad \text { Basal medium } & - & +^{*} \\ \text { Glycerol } & - & +^{*} \\ \quad \text { Sorbitol } & - & - \\ \quad \text { Mannitol } & \pm \dagger & + \\ \text { Malate as an energy source } & - & - \\ \text { Gas from malate + glucose } & + & \pm \\ \text { Citrate as an energy source at pH 8.0 } & \pm \\ \text { Catalase (in presence of heated blood) } & \\ \text { all strains positive, - = all strains negative, } \pm=\text { some strains positive and some nega- } \\ =\text { negative or aerobic only. }\end{array}$

\section{Action on polyhydroxy alcohols}

Glycerol. A test separating Streptococcus faecalis from $S$. faecium by their action on glycerol, the former fermenting it anaerobically and the latter fermenting it aerobically or not at all, was developed from the work of Gunsalus (1947). He noted that organisms able to ferment glycerol anaerobically did so more rapidly when fumarate was added to the medium as an exogenous hydrogen acceptor. Experiments with a soft agar medium confirmed this finding and revealed that a separation based on glycerol fermentation could only be achieved by adding fumarate (sodium salt $0.5 \%, \mathrm{w} / \mathrm{v}$ ) to the medium. In the absence of fumarate one strain of $S$. faecalis (NCIB 370) fermented glycerol aerobically only; three other strains fermented it aerobically and gave anaerobically fermenting mutants. Deibel et al. (1963) had found fumarate useful in this test but observed that one strain of $S$. faecalis fermented glycerol aerobically only while one strain of $S$. faecium fermented glycerol anaerobically, so limiting the value of the test. In these instances a further test based on glycerol metabolism might prove useful, namely the ability to form hydrogen peroxide from glycerol. Gunsalus (1947) observed that streptococci which fermented glycerol only aerobically, formed $\mathrm{H}_{2} \mathrm{O}_{2}$ in the process. Of the strains studied here all those identified as $S$. faecium and able to use glycerol formed $\mathrm{H}_{2} \mathrm{O}_{2}$ on glycerol heated blood o-dianisidine agar. No $S$. faecalis strain, 
including the one that showed a strictly aerobic action in the absence of fumarate, formed $\mathrm{H}_{2} \mathrm{O}_{2}$ on this medium.

Mannitol and sorbitol. Both these hexitols were fermented aerobically and anaerobically by all the Streptococcus faecalis strains and by some of the $S$. faecium strains. The hexitol-fermenting $S$. faecium strains, however, formed $\mathrm{H}_{2} \mathrm{O}_{2}$ on hexitol heated blood $o$-dianisidine agar and the $S$. faecalis strains did not. Therefore inability to ferment these hexitols, or the production of $\mathrm{H}_{2} \mathrm{O}_{2}$ from them when they were used, proved useful in separating $S$. faecium from $S$. faecalis.

\section{Hydrogen peroxide formation on heated blood o-dianisidine agar}

All the organisms identified as Streptococcus faecium but none identified as $S$. faecalis formed $\mathrm{H}_{2} \mathrm{O}_{2}$ on heated blood $o$-dianisidine basal agar. The $\mathrm{H}_{2} \mathrm{O}_{2}$ reaction by $\boldsymbol{S}$. faecium, although distinct, did not cover such a wide area around the growth as it did when a utilizable polyhydroxy alcohol was present. The addition of glucose to the medium inhibited the production of an $\mathrm{H}_{2} \mathrm{O}_{2}$ reaction by all but three strains of $S$. faecium. Consistent results for $\mathrm{H}_{2} \mathrm{O}_{2}$ formation were only obtained when the inocula used had been grown on aerobically incubated slopes. Some strains of $S$. faecalis formed traces of $\mathrm{H}_{2} \mathrm{O}_{2}$ when the inocula were not fully adapted to aerobic conditions as, for instance, when they were taken from static broth cultures.

\section{Greening on blood agar}

Deibel et al. (1963) differentiated the non-haemolytic enterococci on sheep blood agar: Streptococcus faecium but not $S$. faecalis gave a strong greening reaction. A similar finding was made in the present work with ox blood and horse blood agars. The clearest results were obtained with surface inoculated cultures.

The addition of glucose $(1 \%, \mathrm{w} / \mathrm{v})$ to the blood media had the effect of lysing red cells under and around the growth of Streptococcus faecium but not those under and around the $S$. faecalis growth. In all but three instances the $S$. faecium strains did not cause greening. Since these strains were those which formed $\mathrm{H}_{2} \mathrm{O}_{2}$ on heated blood o-dianisidine glucose agar, the relationship of the greening reaction with $\mathrm{H}_{2} \mathrm{O}_{2}$ production with unlysed blood agar, with and without added glucose and $o$-dianisidine, was examined. The areas of greening corresponded with the $\mathrm{H}_{2} \mathrm{O}_{2}$ areas and glucose had a similar effect on both. This circumstantial evidence suggests that greening by the $S$. faecium strains is caused by the $\mathrm{H}_{2} \mathrm{O}_{2}$ they form.

\section{Catalase activity}

Catalase activity on heated blood agar was of some differential value in that 15 of 18 strains of Streptococcus faecalis were positive whilst all strains of $S$. faecium were negative. No organism produced pseudocatalase.

\section{Malate and citrate dissimilation}

The following tests were developed from methods used to identify strains of Streptococcus faecalis and $S$. faecium from silage (Whittenbury, 1956).

Malate. All but two of the strains of Streptococcus faecalis used malate as an energy source; the two exceptions had no action on malate. All the strains of $S$. faecium dissimilated malate but did not use it as an energy source. With both types 
of organism there was an increase in $\mathrm{pH}$ value, indicating decarboxylation; gas $\left(\mathrm{CO}_{2}\right)$ production was frequently observed (always when the tubes were heated in boiling water); acetoin was detected, with $\boldsymbol{S}$. faecalis there was a marked increase in amount of growth over that in the basal medium.

A more precise test was obtained when glucose $(2 \cdot 0 \%, \mathrm{w} / \mathrm{v})$ was included in the medium. In this case Streptococcus faecalis acidified the medium and had no effect on the malate. Streptococcus faecium, on the other hand, fermented the glucose and simultaneously dissimilated the malate so that initially the $\mathrm{pH}$ value decreased but finally rose to $\mathrm{pH} 7 \cdot \mathbf{0}$ or higher. Gas production was vigorous; a light tapping of the tube at 2-3 days frequently resulted in an effervescence which forced the seals out of the tubes. Acetoin formation from malate was not investigated in this medium since many strains form acetoin from glucose.

Measurements were made of glucose disappearance, $\mathrm{pH}$ value and growth in various concentrations of malate and glucose. This showed that the vigorous dissimilation of malate by Streptococcus faecium in the presence of glucose reflected a great increase of growth over that developing in the medium containing malate but no added glucose. With $S$. faecalis glucose had a diauxie effect on malate utilization; glucose-grown cocci adapted to malate only when glucose had disappeared from the medium. Consequently in a medium containing excess glucose growth conditions became unfavourable before adaptation was possible. These results indicate that $S$. faecalis and $S$. faecium metabolized malate by different pathways. There is evidence (Whittenbury \& Playne, unpublished) which shows that $S$. faecium carries out a non-energy-yielding dissimilation of malate under anaerobic conditions; acetoin, lactate and carbon dioxide are the principal end-products. Streptococcus faecalis, on the other hand, carries out an energy-yielding fermentation of malate; acetoin, lactate, formate, acetate, carbon dioxide and ethanol are the major end-products. Acetate and formate are probably the final products of a phosphoroclastic split of pyruvate to formate and acetyl phosphate, the acetyl phosphate giving rise to adenosine triphosphate and acetate.

Citrate utilization. Deibel et al. (1963) found the ability to use citrate a valuable test; all their strains of Streptococcus faecalis used citrate as an energy source, but only a few strains of $S$. faecium did so. A similar finding (Whittenbury, 1956) led to the development of a medium in which only $S$. faecalis used citrate. It was observed that as the initial $\mathrm{pH}$ value of the medium was increased from $\mathrm{pH} 6.0$ to $\boldsymbol{7 \cdot 0}$ fewer strains of $\boldsymbol{S}$. faecium were able to use citrate and in a medium initially at pH 8.0 none did. The changes observed in the absence of glucose were acetoin production, increase in $\mathrm{pH}$ value, gas $\left(\mathrm{CO}_{2}\right)$ production and increased growth over that in the basal medium. Glucose $(2 \cdot 0 \%, \mathrm{w} / \mathrm{v})$ had a diauxie effect on citrate fermentation by both types of organism.

Other tests. No other differential tests were devised. An attempt, however, was made to separate the organisms on their metabolism of serine and arginine. Deibel $\&$ Niven (1960) reported that Streptococcus faecalis and its varieties, but not $S$. faecium, deaminated serine and used it as an energy source. In the present work some strains of both species were found to use serine whilst others did not. Deibel (1960) noted that whereas both species deaminated arginine, only $\boldsymbol{S}$. faecalis used it as an energy source. Strains of both species studied here, however, derived benefit from arginine $(0 \cdot 3 \%, \mathrm{w} / \mathrm{v})$ in the complex basal medium. Strains of $S$. faecium 
obtained least; these gave twice the amount of growth observed in the basal medium, whilst $S$. faecalis gave 4 to 5 times more growth. One strain of $S$. faecium did not hydrolyse arginine; it proved a useful control since the addition of arginine to the basal medium did not affect its growth. Glucose had a diauxic effect on the arginine metabolism of the several strains of $S$. faecalis tested, glucose-grown inocula using arginine only when glucose was no longer detectable. Arginine-grown inocula, however, used both glucose and arginine simultaneously. This diauxie effect was not observed with $S$. faecium.

\section{DISCUSSION}

The enterococci were conveniently separated into two species, Streptococcus faecalis and $S$. faecium. Among the organisms identified as $S$. faecalis were those recognizable as $S$. faecalis (non-haemolytic and non-proteolytic), $S$. zymogenes (haemolytic and sometimes proteolytic), and S. liquefaciens (non-haemolytic and proteolytic); apart from differences in haemolytic, proteolytic and one or two fermentative properties these organisms constitute a fairly homogeneous group. Of the organisms identified as $\boldsymbol{S}$. faecium some were regarded as 'typical'-those fermenting arabinose, melibiose and mannitol and, aerobically only, glyceroland some were identified as $S$. durans-those fermenting glycerol aerobically only but failing to ferment arabinose, melibiose and mannitol. Haemolysis did not seem to be a reliable characteristic of $S$. durans as one strain (498) lost its haemolytic activity. Deibel et al. (1963) also observed the instability of this character among their strains of $S$. durans. Other organisms identified here as $S$. faecium possessed various ranges of properties and occupied intermediate positions between the 'typical' $S$. faecium and $S$. durans. The one motile strain examined and identified as $S$. faecium appears to be similar to the yellow pigmented, motile streptococci described by Graudal (1952), to the motile enterococci described by Langston, Gutierrez \& Bouma (1960), possibly to those described in the references listed by Hugh (1959) and to the motile Group D streptococcus mentioned by Sherman (1938). Apart from its ability to ferment inulin and loss of ability to hydrolyse arginine within a 4-year period, it is very similar to the 'typical' $S$. faecium.

Of the established tests used in this study only tellurite tolerance and reducing activity completely differentiated the organisms; the other commonly used tests were, for various reasons, of limited value. Of the new or modified tests used, fermentation of glycerol in a soft agar medium containing fumarate, hydrogen peroxide formation from polyhydroxy alcohols and ability to ferment them, hydrogen peroxide formation on a medium containing no added sugar or polyhydroxy alcohol, citrate fermentation and dissimilation of malate in the presence of glucose seem to be the most useful. Catalase activity and the ability to use malate as an energy source were also useful but did not differentiate the organisms completely. The practical value of these tests in the routine identification of enterococci remains to be assessed from studies of larger collections of enterococci from divers sources.

The author wishes to thank Dr T. Gibson for advice given during this work and during the preparation of the manuscript. 


\section{REFERENCES}

Barnes, E. M. (1956). Tetrazolium reduction as a means of differentiating Streptococcus faecalis from Streptococcus faecium. J. gen. Microbiol. 14, 57.

BarritT, M. M. (1936). The intensification of the Voges-Proskauer reaction by addition of $\alpha$-naphthol. $J$. Path. Bact. 42, 441.

Brown, J. H. (1919). The use of blood agar for the study of streptococci. Rockefeller Inst. med. Res. Monogr. no. 9.

Chesbro, W. R. \& Evans, J. B. (1959). Factors affecting the growth of enterococci in highly alkaline media. J. Bact. 78, 858 .

DEIBEL, R. H. (1960). Arginine as an energy source for the growth of Streptococcus faecalis. Bact. Proc. p. 163.

Deibel, R. H., Lake, D. E. \& Niven, C. F. (Jr.) (1963). Physiology of the enterococei as related to their taxonomy. J. Bact. 86, 1275.

DeIbel, R. H. \& Niven, C. F. (Jr.) (1960). Lipoic acid and the fermentation of serine and malate by Streptococcus faecalis. Bact. Proc. p. 164.

Graudal, H. (1952). Motile streptococci. Acta path. microbiol. scand. 31, 46.

Gunsalus, I. C. (1947). Products of anaerobic glycerol fermentation by Streptococcus faecalis. J. Bact. 54, 239.

HUGH, R. (1959). Motile streptococci isolated from oropharyngeal region. Can. J. Microbiol. 5, 351.

KEDDIE, R. M. (1959). The properties and classification of lactobacilli isolated from grass and silage. J. appl. Bact. 22, 403.

KJELLANDER, J. (1960). Enteric streptococci as indicators of fecal contamination of water. Acta path. microbiol. scand. suppl. 136.

Lake, D. E., Deibel, R. H. \& Niven, C. F. (Jr.) (1957). The identity of Streptococcus faecium. Bact. Proc. p. 13.

Langston, C. W., Gutierrez, J. \& Bouma, C. (1960). Motile enterococci (Streptococcus faecium var. mobilis var. n.) isolated from grass silage. J. Bact. 80, 714.

Niven, C. F., Smiley, K. L. \& Sherman, J. M. (1942). The hydrolysis of arginine by streptococci. J. Bact. 43, 651 .

OLsen, E. (1949). Studies on the Intestinal Flora of Infants. Copenhagen: Ejnar Munksgaard.

Orla-Jensen, S. (1919). The Lactic Acid Bacteria. Copenhagen: Høst.

Orla-Jensen, S. (1943). The Lactic Acid Bacteria. Ergänzungsband. Copenhagen: Ejnar Munksgaard.

Sharpe, M. E. \& Shattock, P. M. F. (1952). The serological typing of group D streptococci associated with outbreaks of neonatal diarrhoea. J. gen. Microbiol. 6, 150.

Shatтоск, P. M. F. (1955). The identification and classification of Streptococcus faecalis and some associated streptococci. Ann. Inst. Pasteur, Lille, 7, 95.

Sherman, J. M. (1938). The enterococci and related streptococci. J. Bact. 35, 81.

Skadhauge, K. (1950). Studies on enterococci with special reference to the serological properties. Copenhagen: Ejnar Munksgaards.

WhItTenbury, R. (1956). An investigation of the streptococci associated with grass silage. M.Sc. Thesis, University of Edinburgh.

Whittenbury, R. (1961). An investigation of the lactic acid bacteria. Ph.D. Thesis, University of Edinburgh.

Whittensury, R. (1963). The use of soft agar in the study of conditions affecting the utilization of fermentable substrates by lactic acid bacteria. $J$. gen. Microbiol. 32, 375 .

WhITtensury, R. (1964). Hydrogen peroxide formation and catalase activity in the lactic acid bacteria. J. gen. Microbiol. 35, 13. 